\title{
Cow's milk protein allergy awareness and practice among Turkish pediatricians: A questionnaire-survey
}

\author{
Aysel Yüce ${ }^{1}$, Buket Dalgıç ${ }^{2}$ Fügen Çullu-Çokuğraş ${ }^{3}$, Haluk Çokuğraş ${ }^{4}$, Aydan Kansu ${ }^{5}$, \\ Aysugül Alptekin-Sarığlu ${ }^{6}$, Bülent Enis Şekerel ${ }^{7}$ \\ ${ }^{1}$ Department of Pediatric Gastroenterology, Hacettepe University Faculty of Medicine, ${ }^{2}$ Department of Pediatric \\ Gastroenterology, Gazi University Faculty of Medicine, Ankara, ${ }^{3}$ Department of Pediatric Gastroenterology, Istanbul \\ University Cerrahpasa Faculty of Medicine, Istanbul, ${ }^{4}$ Department of Pediatric Allergy, Istanbul University Cerrahpasa \\ Faculty of Medicine, Istanbul, ${ }^{5}$ Department of Pediatric Gastroenterology, Ankara University School of Medicine, Ankara, \\ ${ }^{6}$ Abbott Laboratories, Istanbul, ${ }^{7}$ Department of Pediatric Allergy and Asthma, Hacettepe University Faculty of Medicine, \\ Ankara; Turkey.E-mail: ayuce@hacettepe.edu.tr
}

Received: 3rd May 2017, Revised: 16th June 2017, Accepted: 21st June 2017

SUMMARY: Yüce A, Dalgıç B, Çullu-Çokuğraş F, Çokuğraş H, Kansu A, Alptekin-Sarığlu A, Şekerel BE. Cow's milk protein allergy awareness and practice among Turkish pediatricians: A questionnaire-survey. Turk J Pediatr 2017; 59: 233-243.

Region-specific recommendations for the prevention, diagnosis, and treatment of cow's milk protein allergy (CMPA) are not available in Turkey. This crosssectional questionnaire-survey was designed to evaluate CMPA awareness and practice among Turkish pediatricians. A total of 410 pediatricians were included based on their voluntary participation. Questionnaires elicited demographic data and pediatricians' awareness and practice of CMPA in infants and children. Atopic dermatitis $(91.5 \%)$, diarrhea (88.0\%) and significant blood in stool $(85.9 \%)$ were the most common symptoms considered suggestive of CMPA. Continuation of breast feeding via elimination of CMP containing products from maternal diet was the most commonly selected $(79.0 \%)$ therapeutic option in exclusively breast-fed infants diagnosed with CMPA. Amino acid-based formula was the most commonly selected formula in a non-exclusively breast-fed infant with CMPA, for infants presenting with anaphylaxis $(58.8 \%)$, enterocolitis $(40.7 \%)$ or multiple food allergies $(52.0 \%)$, and also for at-risk infants $(40.2 \%)$. Earliest time to re-challenge was identified to be 6 months by $52.0 \%$ of pediatricians. In conclusion, our findings revealed high awareness of CMPA among Turkish pediatricians in terms of clinical presentation and first priority diagnostic tests. However, CMPA practice among Turkish pediatricians needs to be improved in terms of avoidance of other mammalian milks, selection of therapeutic formulas among non-exclusively breast-fed infants and at-risk infants consistent with guideline-based indications and cost-effectivity.

Key words: cow's milk protein allergy, physician awareness, clinical practice, pediatricians, Turkey.

Diagnosis of cow's milk protein allergy (CMPA) is based on detailed history taking and medical examination followed by an elimination diet which reveals the definitive conclusion for diagnosis as well as the treatment ${ }^{1-3}$. Without an appropriate diagnostic approach, a risk for both over- and under-diagnosis and treatment is likely which restricts the introduction of appropriate diet and maintenance of normal growth and development ${ }^{4,5}$.
Hence, presence of sufficient awareness of the possibility for preventing CMPA as well as guidelines for diagnosis and management of the condition are important given the considerable burden placed by the symptomatic manifestations of CMPA on both the infant and their parents ${ }^{6}$.

Region-specific recommendations tailoring the published evidence to local experiences and challenges for the prevention, diagnosis, and 
treatment of CMPA are not available in Turkey. This cross-sectional questionnaire-based study was therefore designed to evaluate cow's milk protein allergy awareness and practice among pediatricians in Turkey.

\section{Material and Methods}

\section{Study population}

Among the pediatricians attended to the $58^{\text {th }}$ Turkish National Pediatrics Congress (October 22-26, 2014, Antalya, Turkey), Pediatric Gastroenterology Update Meeting (April 10-11, 2015, Adana, Turkey) or 22 ${ }^{\text {nd }}$ National Allergy and Clinical Immunology Congress (November 28-December 2, 2015, Antalya, Turkey), 410 volunteered to participate in this cross-sectional questionnaire-survey based study.

The present study was exempt from the requirement of ethical approval in relation to its questionnaire survey design based on voluntary participation and no patient-specific information was collected.

\section{Data collection}

The study questionnaire was applied via faceto-face method. The questionnaire elicited demographic data and pediatricians' awareness and practice of CMPA in infants and children based on items including number of overall and new cases encountered in the clinical practice per the past month, diagnostic symptoms, diagnostic tests, diagnostic elimination and use of therapeutic formulas [extensively hydrolyzed formula (eHF), amino acid-based formula (AAF), partially hydrolyzed formula (pHF)] with respect to clinical presentations and ongoing feeding patterns and optimal timing for re-challenge. Data were also evaluated with respect to sub-specialties of participants.

\section{Statistical analysis}

Statistical analysis was made using IBM SPSS Statistics (IBM Corp. Released 2012, IBM SPSS Statistics for Windows, Version 21.0. Armonk, NY: IBM Corp). Descriptive statistics were used throughout data analysis which included categorical variables only. Chi-square test with Bonferroni correction, Fisher's exact test and Fisher-Freeman-Halton test were used for the comparison between specialty groups. Data were expressed as percent (\%). p $<0.05$ was considered statistically significant.

\section{Results}

\section{Professional characteristics of pediatricians}

Most of pediatricians were general pediatricians $(56.3 \%)$ and employed at university hospitals $(38.3 \%)$, while overall $50.1 \%$ were in practice for $\leq 10$ years.

Years in practice and type of hospital seemed to differ with respect to sub-specialty type; with higher percentage of general pediatricians (45.9\% for each) as opposed to $21.6 \%$ and $9.3 \%$ of pediatric gastroenterologists, and $16.0 \%$ and $26.0 \%$ of pediatric allergists/immunologists being in practice for $\leq 5$ years and employed at secondary care centers, respectively (Table I). The majority of pediatricians, regardless of their subspecialty, identified the number of overall $(62.4 \%)$ and new $(81.0 \%)$ cases of CMPA encountered in the last month to be less than 4 , with more common encounters of $\geq 5$ cases per month by pediatric gastroenterology and pediatric allergy/immunology specialists (Table I).

\section{CMPA awareness among pediatricians}

Presenting symptoms suggestive of CMPA

Overall, atopic dermatitis $(91.5 \%)$, diarrhea $(88.0 \%)$, flecks or streaks of blood $(87.8 \%)$ or significant blood $(85.9 \%)$ in stool and colic $(83.7 \%)$ were the most common five symptoms considered to be suggestive of CMPA by pediatricians (Table II).

Significant difference was noted between subspecialty types with respect to consideration of anaphylaxis $(\mathrm{p}<0.001)$, angioedema $(\mathrm{p}<0.001)$, dysphagia $(\mathrm{p}<.001)$, vomiting $(\mathrm{p}=0.025)$ and reflux $(p=0.014)$ to be suggestive of CMPA (Table II).

Specifically, angioedema ( $57.1 \%$ vs. $74.2 \%$ and $82.0 \%, \mathrm{p}<0.01)$, dysphagia $(43.7 \%$ vs. $63.9 \%$ and $76.0 \%, \mathrm{p}<0.001)$ and reflux $(70.1 \%$ vs. $83.5 \%$ and $86.0 \%, \mathrm{p}<0.01)$ were considered to be less suggestive of CMPA by general pediatricians as compared with pediatric gastroenterologists and pediatric allergists/ immunologists, respectively (Table II).

Anaphylaxis by a higher percentage of pediatric allergists/immunologists than general pediatricians and pediatric gastroenterologists $(96.0 \%$ vs. $62.3 \%$ and $77.3 \%, p<0.001$, respectively), while vomiting by higher 
Table I. Professional Characteristics of Pediatricians.

\begin{tabular}{|c|c|c|c|c|c|}
\hline & $\begin{array}{l}\text { General } \\
\text { pediatrics }\end{array}$ & $\begin{array}{l}\text { Pediatric } \\
\text { gastroenterology }\end{array}$ & $\begin{array}{l}\text { Pediatric } \\
\text { allergy/ } \\
\text { immunology }\end{array}$ & $\begin{array}{l}\text { Other sub- } \\
\text { specialty }\end{array}$ & Total \\
\hline & $\mathrm{n}(\%)$ & $\mathrm{n}(\%)$ & $\mathrm{n}(\%)$ & $\mathrm{n}(\%)$ & $\mathrm{n}(\%)$ \\
\hline Total & $231(56.3)$ & $97(23.7)$ & $50(12.2)$ & $32(7.8)$ & $410(100.0)$ \\
\hline \multicolumn{6}{|l|}{ Primary care centers } \\
\hline $\begin{array}{l}\text { Maternal and child health } \\
\text { center } \\
\text { Secondary care centers }\end{array}$ & $3(1.3)$ & $0(0.0)$ & $0(0.0)$ & $1(3.1)$ & $4(1.0)$ \\
\hline State hospital & $73(31.6)$ & $4(4.1)$ & $7(14.0)$ & $1(3.1)$ & $85(20.7)$ \\
\hline Private hospital & $33(14.3)$ & $5(5.2)$ & $6(12.0)$ & $3(9.4)$ & $47(11.5)$ \\
\hline \multicolumn{6}{|l|}{ Tertiary care centers } \\
\hline $\begin{array}{l}\text { Training and research } \\
\text { hospital }\end{array}$ & $47(20.3)$ & $18(18.6)$ & $6(12.0)$ & $7(21.9)$ & $78(19)$ \\
\hline $\begin{array}{l}\text { Private/Foundation } \\
\text { University hospital }\end{array}$ & $16(6.9)$ & $11(11.3)$ & $7(14.0)$ & $1(3.1)$ & $35(8.5)$ \\
\hline University hospital & $57(24.7)$ & $58(59.8)$ & $24(48.0)$ & $18(56.3)$ & $157(38.3)$ \\
\hline Missing data & $2(0.9)$ & $1(1.0)$ & $0(0.0)$ & $1(3.1)$ & $4(1.0)$ \\
\hline \multicolumn{6}{|l|}{ Years in practice } \\
\hline$\leq 5$ years & $106(45.9)$ & $21(21.6)$ & $8(16.0)$ & $2(6.3)$ & $137(33.4)$ \\
\hline $6-10$ year & $28(12.1)$ & $23(23.7)$ & $17(34.0)$ & $4(12.5)$ & $72(17.6)$ \\
\hline $11-20$ year & $50(21.6)$ & $31(32.0)$ & $10(20.0)$ & $7(21.9)$ & $98(23.9)$ \\
\hline $21-30$ year & $30(13.0)$ & $18(18.6)$ & $11(22.0)$ & $10(31.3)$ & $69(16.8)$ \\
\hline$\geq 31$ years & $14(6.1)$ & $4(4.1)$ & $3(6.0)$ & $8(25.0)$ & $29(7.1)$ \\
\hline Missing data & $3(1.3)$ & $0(0.0)$ & $1(2.0)$ & $1(3.1)$ & $5(1.2)$ \\
\hline $\begin{array}{l}\text { Overall number of cases } \\
\text { in the last month }\end{array}$ & $\mathrm{n}(\%)$ & $\mathrm{n}(\%)$ & $\mathrm{n}(\%)$ & $\mathrm{n}(\%)$ & $\mathrm{n}(\%)$ \\
\hline $\begin{array}{l}\leq 4 \\
5-8\end{array}$ & $\begin{array}{l}182(78.8) \\
31(13.4)\end{array}$ & $\begin{array}{ll}32 & (33.0) \\
30 & (30.9)\end{array}$ & $\begin{array}{l}14(28.0) \\
16(32.0)\end{array}$ & $\begin{array}{l}28(87.5) \\
3(9.4)\end{array}$ & $\begin{array}{l}256(62.4) \\
80(19.5)\end{array}$ \\
\hline $9-16$ & $13(5.6)$ & $22(22.7)$ & $8(16.0)$ & $0(0.0)$ & $43(10.5)$ \\
\hline $17-32$ & $4(1.7)$ & $8(8.2)$ & $6(12.0)$ & $0(0.0)$ & $18(4.4)$ \\
\hline$\geq 33$ & $1(0.4)$ & $4(4.1)$ & $6(12.0)$ & $1(3.1)$ & $12(2.9)$ \\
\hline Missing data & $0(0.0)$ & $1(1.0)$ & $0(0.0)$ & $0(0.0)$ & $1(0.2)$ \\
\hline \multicolumn{6}{|l|}{$\begin{array}{l}\text { Number of new cases in } \\
\text { the last month }\end{array}$} \\
\hline$\leq 4$ & $210(90.9)$ & $64(66.0)$ & $27(54.0)$ & $31(96.9)$ & $332(81.0)$ \\
\hline $5-8$ & $15(6.5)$ & $24(24.7)$ & $11(22.0)$ & $1(3.1)$ & $51(12.4)$ \\
\hline $9-16$ & $2(0.9)$ & $7(7.2)$ & $5(10.0)$ & $0(0.0)$ & $14(3.4)$ \\
\hline $17-32$ & $2(0.9)$ & $1(1.0)$ & $5(10.0)$ & $0(0.0)$ & $8(2)$ \\
\hline Missing data & $0(0.0)$ & $1(1)$ & $0(0.0)$ & $0(0.0)$ & $1(0.2)$ \\
\hline
\end{tabular}

percentage of pediatric gastroenterologists than general pediatricians and pediatric allergists/ immunologists $(86.6 \%$ vs. $77.1 \%$ and $82.0 \%$, $\mathrm{p}<0.05$, respectively) were considered to be suggestive of CMPA (Table II).

Diagnostic tests in a well-developed infant presenting with flecks or streaks of blood in stool

Amongst diagnostic tests, colonoscopy (81.0\%) was considered the most common "not the first priority" test, followed by detection of amoebic antigens in stool (15.4\%) and stool culture $(11.2 \%)$ in evaluation of a well- 


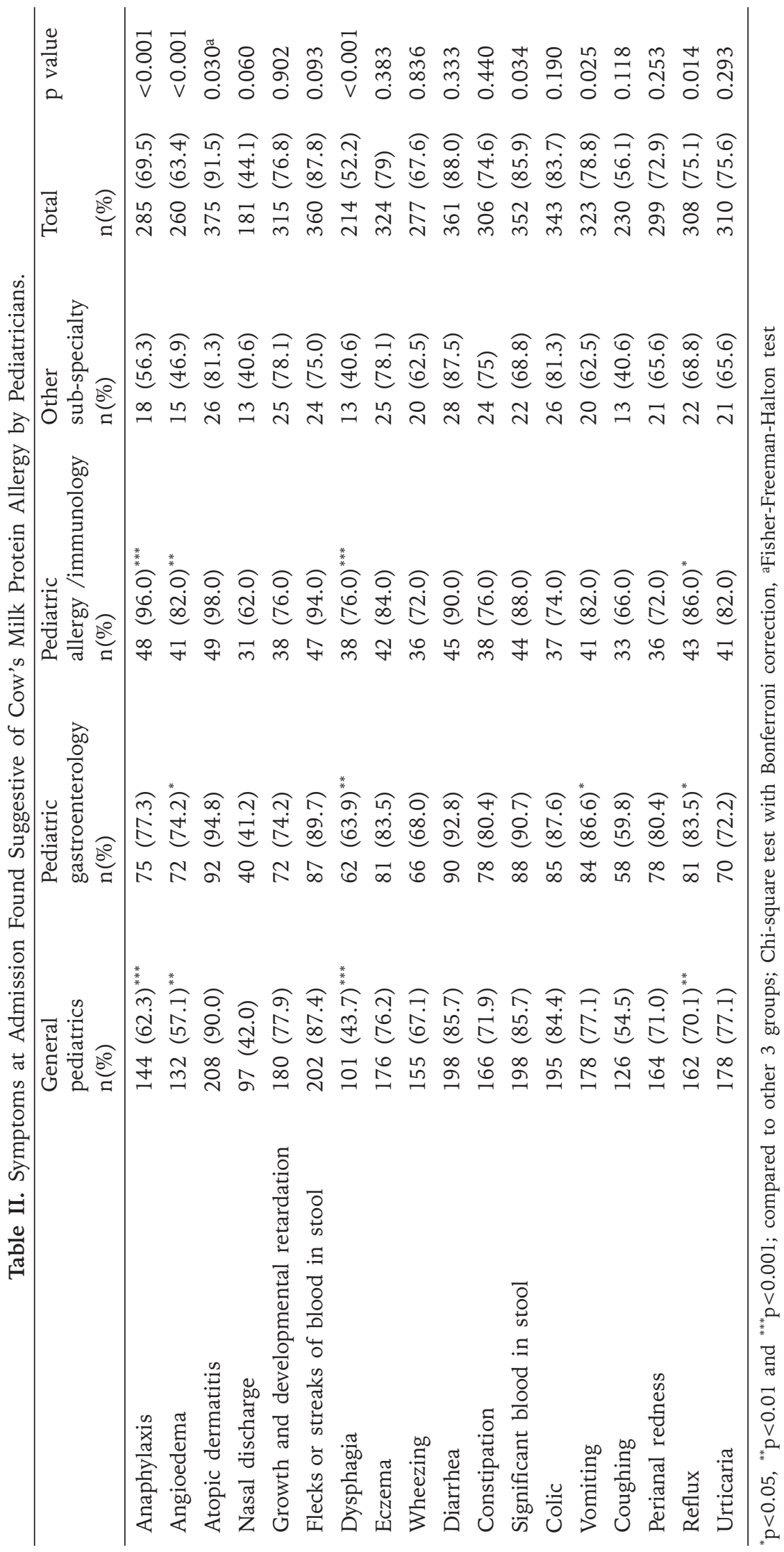




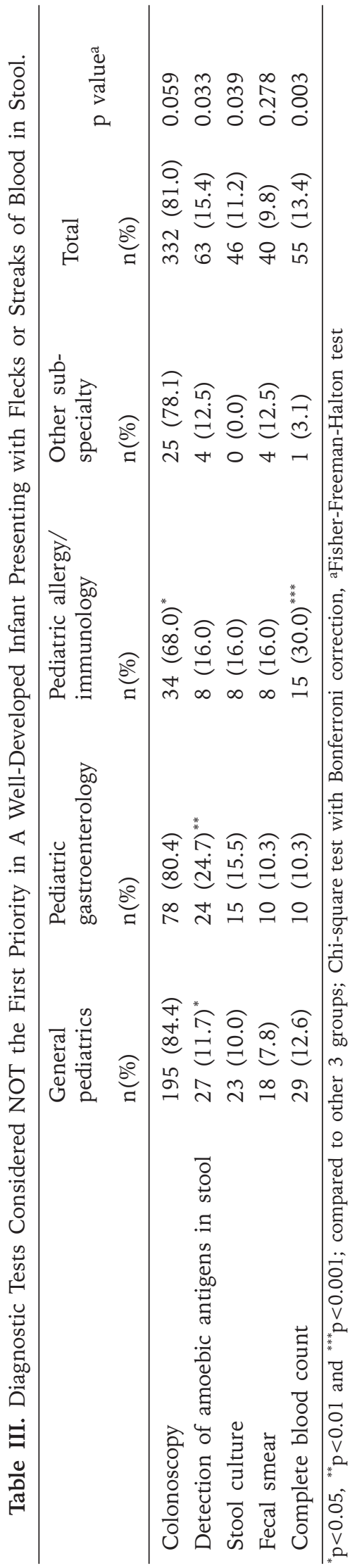

developed infant presenting with flecks or streaks of blood in stool. Detection of amoebic antigens in stool was considered "not the first priority" test by higher percentage of pediatric gastroenterologists than general pediatricians and pediatric allergists/immunologists $(24.7 \%$ vs. $11.7 \%$ and $16.0 \%, \mathrm{p}<0.01$, respectively), while complete blood count (CBC) was considered "not the first priority" test by higher percentage of pediatric allergists/ immunologists than general pediatricians and pediatric gastroenterologists $(30.0 \%$ vs. $12.6 \%$ and $10.3 \%, \mathrm{p}<0.001$, respectively) (Table III).

Colonoscopy was considered the non-priority test by lesser percentage of pediatric allergists/ immunologists than general pediatricians and pediatric gastroenterologists $(68.0 \%$ vs. $84.4 \%$ and $80.4 \%, \mathrm{p}<0.05$, respectively) (Table III).

\section{CMPA practice among pediatricians}

Majority of pediatricians (95.4\%) considered CMPA to be able to develop in an exclusively breast-fed infant (Table IV).

First-line treatment in an exclusively breast-fed infant diagnosed with CMPA

Overall, continuation of breast feeding via elimination of CMP containing products from maternal diet was the most commonly selected $(79.0 \%)$ therapeutic option in exclusively breastfed infants diagnosed with CMPA, followed by AAF (18.3\%). Continuation of breast-feeding and maternal diet CMP elimination (62.0\%) was a less common option with higher rates for AAF preference (34.0\%) for exclusively breast-fed infants among pediatric allergists/ immunologists than other subspecialists (Table IV).

First-line formula in a non-exclusively breast-fed infant with CMPA

Overall, AAF was the most commonly selected formula (48.8\%), followed by eHF $(23.2 \%)$ by pediatricians in a non-exclusively breast-fed infant with CMPA, while pediatric gastroenterologist identified use of eHF (32.0\%) more commonly than other subspecialists (Table IV).

Formula recommendation for infants presenting with anaphylaxis, enterocolitis or multiple food allergies

Overall, AAF $(58.8 \%, 40.7 \%$ and $52.0 \%$ ) was the most commonly selected formula by pediatricians regardless of the subspecialty, 
Table IV. Cow's Milk Protein Allergy (CMPA) Practice among Pediatricians.*

\begin{tabular}{|c|c|c|c|c|c|}
\hline & $\begin{array}{l}\text { General } \\
\text { pediatrics }\end{array}$ & $\begin{array}{l}\text { Pediatric } \\
\text { gastroenterology }\end{array}$ & $\begin{array}{l}\text { Pediatric allergy } \\
\text { /immunology }\end{array}$ & $\begin{array}{l}\text { Other sub- } \\
\text { specialty }\end{array}$ & Total \\
\hline \multicolumn{6}{|l|}{$\begin{array}{l}\text { CMPA may develop in an } \\
\text { exclusively breast-fed infant }\end{array}$} \\
\hline \multicolumn{6}{|c|}{ First-line nutritional recommendation in an exclusively breast-fed infant diagnosed with CMPA } \\
\hline $\begin{array}{l}\text { Introduction of amino acid based } \\
\text { formula }\end{array}$ & $37(16.0)$ & $11(11.3)$ & $17(34.0)$ & $10(31.3)$ & $75(18.3)$ \\
\hline Discontinuation of breast feeding & $1(0.4)$ & $1(1.0)$ & $1(2.0)$ & $0(0.0)$ & $3(0.7)$ \\
\hline $\begin{array}{l}\text { Continuation of breast feeding via } \\
\text { maternal diet elimination }\end{array}$ & $191(82.7)$ & $83(85.6)$ & $31(62.0)$ & $19(59.4)$ & $324(79.0)$ \\
\hline Introduction of goat milk & $1(0.4)$ & $0(0.0)$ & $0(0.0)$ & $1(3.1)$ & $2(0.5)$ \\
\hline $\begin{array}{l}\text { Introduction of lactose-free cow } \\
\text { milk }\end{array}$ & $0(0.0)$ & $0(0.0)$ & $0(0.0)$ & $1(3.1)$ & $1(0.2)$ \\
\hline Missing data & $1(0.4)$ & $2(2.1)$ & $1(2.0)$ & $1(3.1)$ & $5(1.2)$ \\
\hline \multicolumn{6}{|c|}{ First-line formula in a non-exclusively breast-fed infant diagnosed with CMPA } \\
\hline Amino acid based formula & $108(46.8)$ & $47(48.5)$ & $30(60.0)$ & $15(46.9)$ & $200(48.8)$ \\
\hline Extensively hydrolyzed formula & $48(20.8)$ & $31(32.0)$ & $13(26.0)$ & $3(9.4)$ & $95(23.2)$ \\
\hline Partially hydrolyzed formula & $50(21.6)$ & $15(15.5)$ & $4(8.0)$ & $9(28.1)$ & $78(19.0)$ \\
\hline Lactose-free formula & $16(6.9)$ & $2(2.1)$ & $1(2.0)$ & $1(3.1)$ & $20(4.9)$ \\
\hline Age-appropriate standard formula & $5(2.2)$ & $0(0.0)$ & $1(2.0)$ & $2(6.3)$ & $8(2)$ \\
\hline Missing data & $4(1.7)$ & $2(2.1)$ & $1(2.0)$ & $2(6.3)$ & $9(2.2)$ \\
\hline \multicolumn{6}{|c|}{ Formula recommendation for infants presenting with anaphylaxis } \\
\hline Amino acid based formula & $126(54.5)$ & $64(66.0)$ & $34(68.0)$ & $17(53.1)$ & $241(58.8)$ \\
\hline Extensively hydrolyzed formula & $64(27.7)$ & $19(19.6)$ & $6(12.0)$ & $8(25)$ & $97(23.7)$ \\
\hline Partially hydrolyzed formula & $25(10.8)$ & $6(6.2)$ & $6(12.0)$ & $4(12.5)$ & $41(10)$ \\
\hline Age-appropriate standard formula & $12(5.2)$ & $3(3.1)$ & $3(6.0)$ & $2(6.3)$ & $20(4.9)$ \\
\hline Missing data & $4(1.7)$ & $5(5.2)$ & $1(2.0)$ & $1(3.1)$ & $11(2.7)$ \\
\hline \multicolumn{6}{|c|}{ Formula recommendation for infants with multiple food allergies } \\
\hline Amino acid based formula & $110(47.6)$ & $58(59.8)$ & $30(60.0)$ & $15(46.9)$ & $213(52.0)$ \\
\hline Extensively hydrolyzed formula & $71(30.7)$ & $28(28.9)$ & $8(16.0)$ & $14(43.8)$ & $121(29.5)$ \\
\hline Partially hydrolyzed formula & $32(13.9)$ & $7(7.2)$ & $11(22.0)$ & $1(3.1)$ & $51(12.4)$ \\
\hline Age-appropriate standard formula & $12(5.2)$ & $1(1.0)$ & $0(0.0)$ & $1(3.1)$ & $14(3.4)$ \\
\hline Missing data & $6(2.6)$ & $3(3.1)$ & $1(2.0)$ & $1(3.1)$ & $11(2.7)$ \\
\hline \multicolumn{6}{|c|}{ Formula recommendation in infants with enterocolitis as the sole presenting symptom } \\
\hline Amino acid based formula & $77(33.3)$ & $44(45.4)$ & $31(62.0)$ & $15(46.9)$ & $167(40.7)$ \\
\hline Extensively hydrolyzed formula & $33(14.3)$ & $26(26.8)$ & $11(22.0)$ & $3(9.4)$ & $73(17.8)$ \\
\hline Partially hydrolyzed formula & $86(37.2)$ & $17(17.5)$ & $6(12.0)$ & $11(34.4)$ & $120(29.3)$ \\
\hline Age-appropriate standard formula & $29(12.6)$ & $6(6.2)$ & $1(2.0)$ & $2(6.3)$ & $38(9.3)$ \\
\hline Missing data & $6(2.6)$ & $4(4.1)$ & $1(2.0)$ & $1(3.1)$ & $12(2.9)$ \\
\hline $\begin{array}{l}\text { Formula recommendation for infant } \\
\text { feeding }\end{array}$ & & & & & \\
\hline Amino acid based formula & $92(39.8)$ & $34(35.1)$ & $24(48.0)$ & $15(46.9)$ & $165(40.2)$ \\
\hline Extensively hydrolyzed formula & $49(21.2)$ & $16(16.5)$ & $9(18.0)$ & $6(18.8)$ & $80(19.5)$ \\
\hline Partially hydrolyzed formula & $45(19.5)$ & $25(25.8)$ & $9(18.0)$ & $6(18.8)$ & $85(20.7)$ \\
\hline Age-appropriate standard formula & $39(16.9)$ & $17(17.5)$ & $6(12.0)$ & $3(9.4)$ & $65(15.9)$ \\
\hline Missing data & $6(2.6)$ & $5(5.2)$ & $2(4.0)$ & $2(6.3)$ & $15(3.7)$ \\
\hline \multicolumn{6}{|c|}{ Earliest time to re-consider open challenge in an infant diagnosed with CMPA at 2 months of age } \\
\hline 3 months after the onset of diet & $32(13.9)$ & $7(7.2)$ & $9(18.0)$ & $5(15.6)$ & $53(12.9)$ \\
\hline 6 months after the onset of diet & $125(54.1)$ & $42(43.3)$ & $27(54.0)$ & $19(59.4)$ & $213(52.0)$ \\
\hline 9 months after the onset of diet & $22(9.5)$ & $20(20.6)$ & $7(14.0)$ & $3(9.4)$ & $52(12.7)$ \\
\hline 12 months after the onset of diet & $41(17.7)$ & $17(17.5)$ & $6(12.0)$ & $2(6.3)$ & $66(16.1)$ \\
\hline 24 months after the onset of diet & $9(3.9)$ & $7(7.2)$ & $1(2.0)$ & $2(6.3)$ & $19(4.6)$ \\
\hline Missing data & $2(0.9)$ & $4(4.1)$ & $0(0.0)$ & $1(3.1)$ & $7(1.7)$ \\
\hline
\end{tabular}

*: Data is presented as $\mathrm{n}(\%)$. 


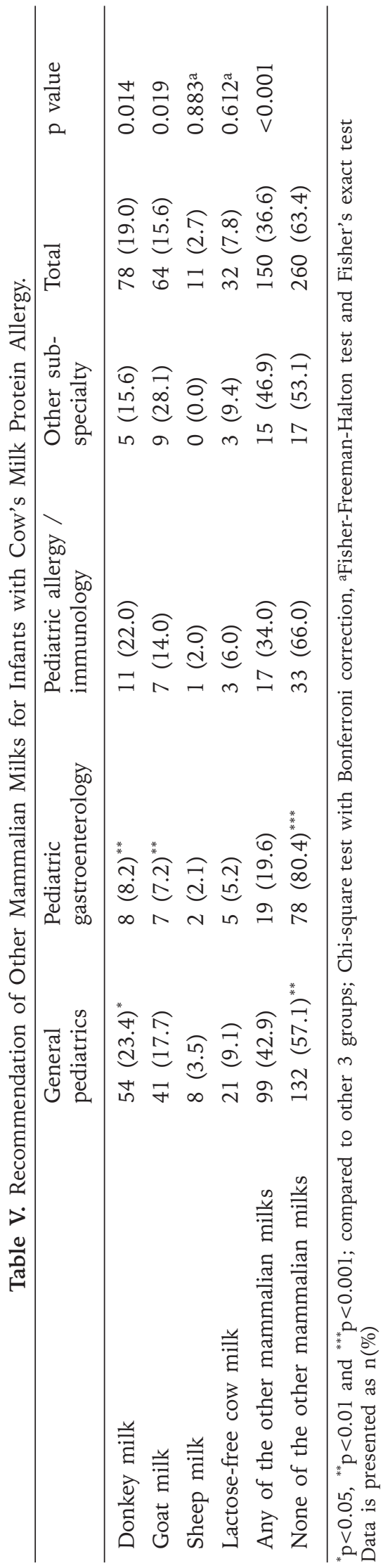

for infants presenting with anaphylaxis, enterocolitis or multiple food allergies, respectively. Albeit considered as the treatment of choice by all pediatricians, AAF was more commonly selected in case of enterocolitis by pediatric allergists/immunologists (62.0\%) than general pediatricians $(33.3 \%)$ and pediatric gastroenterologists $(45.4 \%)$ (Table IV).

Formula recommendation for at-risk infants with no chance of exclusive breast feeding

Overall, in at-risk infants with no chance of exclusive breastfeeding, AAF was the most commonly $(40.2 \%)$ selected formula, as followed equally by eHF (19.5\%) and pHF (20.7\%). Pediatric gastroenterologists $(25.8 \%)$ preferred pHF among at-risk infants more commonly than general pediatricians $(19.5 \%)$ and pediatric allergists/immunologists (18.0\%) (Table IV).

Earliest time to re-challenge

Overall, earliest time to re-challenge with cow's milk after maintaining a therapeutic diet was identified to be 6 months by $52.0 \%$ of pediatricians with consideration of longer than 9-month intervals more commonly by pediatric gastroenterologists $(45.3 \%)$ than general pediatricians $(31.1 \%)$ and pediatric allergists/immunologists (28.0\%) (Table IV).

Recommendation of other mammalian milks for infants with CMPA

Overall, $36.6 \%$ of pediatricians considered any other types of mammalian milks to be appropriate for infants with CMPA with donkey milk $(19.0 \%)$ and goat milk $(15.6 \%)$ as the most commonly selected types (Table V).

Overall $63.4 \%$ of participants, with significantly higher percentage of pediatric gastroenterologists (80.4\%) than general pediatricians $(57.1 \%)$ and pediatric allergists/immunologists $(66.0 \%)$, considered none of other types of mammalian to be appropriate in infants with CMPA $(\mathrm{p}<0.001)$ (Table V).

\section{Discussion}

Overall, the majority of pediatricians considered atopic dermatitis, diarrhea, blood in stool and colic to be suggestive of CMPA; considered colonoscopy not to be the first-priority test in evaluation of a well-developed infant presenting with flecks or streaks of blood in stool; and considered CMPA to be able to 
develop in an exclusively breast-fed infant and continuation of breast feeding via elimination of CMP containing products from maternal diet to be the treatment of choice in this group. AAF was the most commonly selected formula by pediatricians in a non-exclusively breast-fed infant with CMPA $(48.8 \%)$, for infants presenting with anaphylaxis $(58.8 \%)$, enterocolitis $(40.7 \%)$ or multiple food allergies $(52.0 \%)$ and in at-risk infants with no chance of exclusive breastfeeding $(40.2 \%)$. Earliest time to re-challenge was considered to be 6 months by $52.0 \%$ of pediatricians, while use of any of the other mammalian milks was considered appropriate in infants with CMPA by $36.6 \%$. Significant difference was noted between pediatric sub-specialties with respect to recognition of symptoms, selection of first-line treatment among infants with or without exclusive breast-feeding, formula recommendation for at-risk infants with no chance of exclusive breast feeding, earliest time to re-challenge and appropriateness of using other types of mammalian milk in CMPA.

Symptoms and signs related to CMPA has been suggested to involve many different organ systems, mostly the skin, the gastrointestinal system and the respiratory tract ${ }^{4}$, including oral and perioral swelling, dysphagia, food impaction, vomiting, regurgitation, dyspepsia, early satiety, anorexia, food refusal, diarrhea, rectal bleeding, failure to thrive, abdominal pain, severe colic, and persistent constipation often with perianal abnormalities. ${ }^{4}$ CMPA related symptoms are considered to be rather variable and nonspecific in most cases and none of the manifesting symptoms is pathognomonic ${ }^{4,7}$. Besides, there is a large overlap with appearance of the same symptoms in CMP IgE-positive and IgEnegative patients, particularly in children with gastrointestinal manifestations ${ }^{4,8}$. Accordingly, majority of our pediatricians considered atopic dermatitis, diarrhea, blood in stool and colic to be suggestive of CMPA.

Overall, colonoscopy was the most common diagnostic test considered by pediatricians $(85.5 \%)$ to be not the first priority in evaluation of a well-developed infant presenting with flecks or streaks of blood in stool. This seems consistent with consideration of upper and/ or lower endoscopies with multiple biopsies to be appropriate in patients with otherwise unexplained significant and persistent gastrointestinal symptoms, failure to thrive, or iron deficiency anemia, and the fact that macroscopic lesions and histological findings are neither sensitive nor specific for $\mathrm{CMPA}^{9}$.

Majority of pediatricians in this study considered CMPA to be able to develop in an exclusively breast-fed infant and indicated continuation of breast feeding via elimination of CMP containing products from maternal diet as the treatment of choice for diagnostic elimination in this group. This seems consistent with the diagnostic elimination recommended in exclusively breast-fed infants that is elimination of the cow's milk-containing products from the maternal diet ${ }^{4,10,11}$.

Although practice patterns identified in this study indicated management of exclusively breast-fed infants with CMPA to be in accordance with European Society of Pediatric Gastroenterology Hepatology and Nutrition (ESPGHAN) guidelines ${ }^{4}$, inappropriate practice patterns were noted in the first-line treatment among infants not exclusively breast-fed. AAF was found to be the most commonly selected formula by pediatricians in a non-exclusively breast-fed infant with CMPA (48.8\%), while eHF was selected in this group of infants only by $23.2 \%$ of pediatricians. Although this seems in accordance with the statement that cow's milk-based formula and any complementary food containing CMP should be avoided for infants that are not exclusively breastfed ${ }^{4,12}$, the first line treatment is expected to be eHF in this group ${ }^{4,6,13,14}$ in term of its lower cost and higher efficacy in inducing tolerance than $\mathrm{AAF}^{15,16 .}$

Use of pHF based on CMP or other mammalian protein as well as milk from other mammalian species are not recommended for infants with $\mathrm{CMPA}^{6,12,17}$. This is due to inclusion of large peptides with immunogenicity in the molecule and low tolerability rates for $\mathrm{pHF}^{13,18}$ and the risk of cross-reactivity and being not nutritionally adapted to the needs of the infant for other mammalian milks $s^{6,17,19}$. Notably, besides consideration of use of other mammalian milks to be appropriate in infants with CMPA by $36.6 \%$ of pediatricians, the rates for selection of $\mathrm{pHF}$ as the first-line formula in not-exclusively breast-fed infants (19.0\%) and infants presenting with anaphylaxis $(10.0 \%)$, 
enterocolitis $(29.3 \%)$ or multiple food allergies $(12.4 \%)$ were non-negligible in our study.

Nonetheless, our findings revealed that AAF was also the formula most commonly selected by pediatricians for infants presenting with anaphylaxis $(58.8 \%)$, enterocolitis $(40.7 \%)$ or multiple food allergies (52.0\%). This seems in line agreement with reported indications of AAF including severe cases such as anaphylaxis, enteropathy, eosinophilic esophagitis and food protein induced enterocolitis along with cases of multiple system involvement, multiple food allergies and intolerance to $\mathrm{eHF}^{4,6,13,14}$.

While eHF and AAF remove allergenicity, in CMPA prevention the loss of immunogenicity also prevents the immune system from developing tolerance to milk proteins ${ }^{18}$. As a result, pHF is commonly used for prevention of allergy ${ }^{13}$ and when exclusive breastfeeding is impossible, all at-risk infants are recommended to receive a pHF for prevention of allergy until their risk has been assessed by a healthcare provider $^{1,6,20}$.

Although efficacy of using both pHF and eHF were shown for the prevention of allergy in infants at high risk of allergy ${ }^{21-23}$, AAF is not recommended in prevention of CMPA. ${ }^{6}$ In this regard, it should be noted that AAF was also the most commonly selected formula $(40.2 \%)$ for at-risk infants with no chance of exclusive breastfeeding in our study, with selection of pHF in this group of infants only by $20.7 \%$ of pediatricians.

Hence, our findings emphasize that practice patterns in use of formula-based therapy of infants with CPMA in clinical practice in Turkey should be improved in terms of compatibility with therapeutic indications specified for each formula.

Conventional approach considers a re-challenge with cow's milk after maintaining a therapeutic diet for at least 4-6 months in case of IgEnegative infants with mild symptoms, while up to at least 12 months in case of highIgE positivity or severe reactions, to avoid unnecessary prolongation of restrictive diet and the likelihood of improper growth ${ }^{1,4}$. Accordingly, earliest time to re-challenge with cow's milk after maintaining a therapeutic diet was identified to be 6 months by half of pediatricians in this study, while consideration of longer than 9-month intervals was more common among pediatric gastroenterologists.

Considering differences in practice patterns with respect to sub-specialty types, both gastroenterologists and allergists/immunologists seem to be more aware of clinical manifestations and spectrum of presenting symptoms of CMPA as compared with general pediatricians who tended to underestimate diagnostic value of anaphylaxis, angioedema, dysphagia, reflux and vomiting. Given the likelihood of these symptoms to mimic severe allergic reactions associated with primary atopy and functional gastrointestinal disorders ${ }^{10}$, our findings emphasize that differential diagnosis of CMPA should be more carefully considered by general pediatricians. Nonetheless, it should be noted that half of general pediatricians participated in this study were employed at secondary care hospitals and in practice for $\leq 5$ years.

One-third of pediatric allergists/immunologists indicated AAF as the treatment of choice for exclusively breast-fed infants with CMPA, and considered colonoscopy as the first priority test in a well-developed infant presenting with flecks or streaks of blood in stool. Higher tendency to prescribe AAF among pediatric allergists/immunologists seems to be associated with higher likelihood of encountering cases with anaphylaxis than proctocolitis in their clinical practice. Nonetheless, their practice should be improved in terms of selection of diagnostic tests and treatments based on high index of suspicion, evidence-based indication and cost-effectivity.

Pediatric gastroenterologists seem to have more appropriate practice patterns in CMPA with respect to evidence-based therapeutic formula selection among non-exclusively breast-fed infants and at risk infants, avoidance of the mammalian type milks and optimal time to re-challenge.

These findings seem notable given that primary care practice is generally adapted to non-IgE mediated CMPA with consideration of complex dietary guidance for CMPA by referral centers when it is part of multiple food allergies or of an eosinophilic disorder ${ }^{2}$.

Certain limitations to this study should be considered. First, albeit the high response rate, due to relatively low sample, generalizing 
our findings to entire population of Turkish pediatricians seems difficult. Secondly, relying on voluntary participation, likelihood of systematic differences between responders and non-responders, and thus that our findings are presumed to be biased by a lack of respondents seems another limitation. Nevertheless, despite these certain limitations, given the paucity of the solid information available on this subject, our findings represent a valuable contribution to the data available on CMPA awareness and practice among Turkish pediatricians.

In conclusion, our findings revealed overall high awareness of CMPA among Turkish pediatricians in terms of clinical presentation and first priority diagnostic tests of the disease and appropriate management of CMPA among exclusively breast-fed infants in accordance with guidelines. However, CMPA practice among Turkish pediatricians, non-gastroenterologists in particular, needs to be improved in terms of selection of therapeutic formulas among non-exclusively breast-fed infants and at-risk infants consistent with guideline-based on indications. Our findings emphasize the need for more comprehensive evaluation of clinical manifestations and differential diagnosis of the disease in the secondary care practice, and selection of more appropriate and cost-effective diagnostic and therapeutic modalities in the tertiary care practice. Obviously, development of national guidelines for the diagnosis, prevention and management of suspected CMPA in infants and children in Turkey is necessary to be able to standardize practice patterns in real-life clinical practice consonant with healthcare policies and product availability and affordability.

\section{Acknowledgments}

We thank Cagla Ayhan, MD and Prof. Sule Oktay, MD, PhD. from KAPPA Consultancy Training Research Ltd, Istanbul who provided editorial support and Mehmet Berktas, MD, MICR from KAPPA Consultancy Training Research Ltd, Istanbul who performed statistical analysis funded by Abbott Nutrition Turkey.

\section{REFERENCES}

1. Boyce JA, Assa'ad A, Burks AW, et al.; NIAIDSponsored Expert Panel. Guidelines for the Diagnosis and Management of Food Allergy in the United States: Summary of the NIAID-Sponsored Expert Panel Report. J Allergy Clin Immunol 2010; 126: 1105-1118.
2. Dupont C. Diagnosis of cow's milk allergy in children determining the gold standard? Expert Rev Clin Immunol 2014; 10: 257-267.

3. Fiocchi A, Brozek J, Schünemann $\mathrm{H}$, et al. World Allergy Organization (WAO) Diagnosis and Rationale for Action against Cow's Milk Allergy (DRACMA) Guidelines. World Allergy Organ 2010; 3: 57-161.

4. Koletzko S, Niggemann B, Arato A, et al; European Society of Pediatric Gastroenterology, Hepatology, and Nutrition. Diagnostic approach and management of cow's-milk protein allergy in infants and children: ESPGHAN GI Committee practical guidelines. J Pediatr Gastroenterol Nutr 2012; 55: 221-229.

5. Eggesbo M, Botten G, Halvorsen R, Magnus P. The prevalence of CMA/CMPI in young children: the validity of parentally perceived reactions in a population-based study. Allergy 2001; 56: 393-402.

6. Vandenplas Y, Abuabat A, Al-Hammadi S, et al. Middle East Consensus Statement on the Prevention, Diagnosis, and Management of Cow's Milk Protein Allergy. Pediatr Gastroenterol Hepatol Nutr 2014; 17: 61-73.

7. Mazigh S, Yahiaoui S, Ben Rabeh R, Fetni I, Sammoud A. Diagnosis and management of cow's protein milk allergy in infant. Tunis Med 2015; 93: 205-211.

8. Shek LP, Bardina L, Castro R, Sampson HA, Beyer K. Humoral and cellular responses to cow milk proteins in patients with milk-induced IgE-mediated and nonIgE-mediated disorders. Allergy 2005; 60: 912-919.

9. Nielsen RG, Fenger C, Bindslev-Jensen C, Husby S Eosinophilia in the upper gastrointestinal tract is not a characteristic feature in cow's milk sensitive gastro-oesophageal reflux disease. Measurement by two methodologies. J Clin Pathol 2006; 59: 89-94.

10. Brill H. Approach to milk protein allergy in infants Can Fam Physician 2008; 54: 1258-1264.

11. Kramer MS, Kakuma R. Maternal dietary antigen avoidance during pregnancy or lactation, or both, for preventing or treating atopic disease in the child. Cochrane Database Syst Rev 2006; 3: CD000133.

12. Host A, Koletzko B, Dreborg S, et al. Dietary products used in infants for treatment and prevention of food allergy. Joint statement of the European Society for Paediatric Allergology and Clinical Immunology (ESPACI) Committee on Hypoallergenic Formulae and the European Society for Paediatric Gastroenterology, Hepatology and Nutrition (ESPGHAN) Committee on Nutrition. Arch Dis Child 1999; 81: 80-84.

13. Vandenplas Y, De Greef E, Devreker T. Treatment of cow's milk protein allergy. Pediatr Gastroenterol Hepatol Nutr 2014; 17: 1-5.

14. Isolauri E, Sutas Y, Makinen-Kiljunen S, Oja SS, Isosomppi R, Turjanmaa K. Efficacy and safety of hydrolyzed cow milk and amino acid-derived formulae in infants with cow milk allergy. J Pediatr 1995; 127: 550-557.

15. Taylor RR, Sladkevicius E, Panca M, Lack G, Guest JF. Cost-effectiveness of using an extensively hydrolysed formula compared to an amino acid formula as firstline treatment for cow milk allergy in the UK. Pediatr Allergy Immunol 2012; 23: 240-249. 
16. Berni Canani R, Nocerino R, Terrin G, et al. Formula selection for management of children with cow's milk allergy influences the rate of acquisition of tolerance: a prospective multicenter study. J Pediatr 2013; 163: 771-777.

17. Jarvinen KM, Chatchatee P. Mammalian milk allergy: clinical suspicion, cross-reactivities and diagnosis. Curr Opin Allergy Clin Immunol 2009; 9: 251-258.

18. Crittenden RG, Bennett LE. Cow's milk allergy: a complex disorder. J Am Coll Nutr 2005; 24(6 Suppl): S582-591.

19. Ehlayel M, Bener A, Abu Hazeima K, Al-Mesaifri F. Camel milk is a safer choice than goat milk for feeding children with cow milk allergy. ISRN Allergy 2011; 2011: 391641.

20. Greer FR, Sicherer SH, Burks AW; American Academy of Pediatrics Committee on Nutrition; American Academy of Pediatrics Section on Allergy and Immunology. Effects of early nutritional interventions on the development of atopic disease in infants and children: the role of maternal dietary restriction, breastfeeding, timing of introduction of complementary foods, and hydrolyzed formulas. Pediatrics 2008; 121: 183-191.
21. von Berg A, Filipiak-Pittroff B, Krämer U, et al.; GINIplus study group. Allergies in high-risk schoolchildren after early intervention with cow's milk protein hydrolysates: 10-year results from the German Infant Nutritional Intervention (GINI) study. J Allergy Clin Immunol 2013; 131: 1565-1573.

22. Marini A, Agosti M, Motta G, Mosca F. Effects of a dietary and environmental prevention programme on the incidence of allergic symptoms in high atopic risk infants: three years' follow-up. Acta Paediatr Suppl 1996; 414: 1-21.

23. Vandenplas Y, Hauser B, Van den Borre C, et al. The long-term effect of a partial whey hydrolysate formula on the prophylaxis of atopic disease. Eur J Pediatr 1995; 154: 488-494. 